\title{
Sair do Paradigma da Dívida - A partir da leitura de João Vário
}

\author{
SiLvina Rodrigues Lopes \\ Universidade Nova de Lisboa
}

\begin{abstract}
RESUMO: O CARÁTER DE AFIRMAÇÃO NA POESIA DE JOÃO VÁRIO ENCERRA, PARADOXALMENTE, O ENIGMA DESENCADEANDO ENIGMAS, NÃO SE RESTRINGINDO À DEPENDÊNCIA DE QUALQUER ESPÉCIE DE SABER.
\end{abstract}

ABSTRACT: THE CHARACTER OF AFFIRMATION IN THE JOÃO VÁRIO'S POETRY TERMINATES PARADOXICALLY THE ENIGMA UNCHAINING ENIGMAS, NOT RESTRICTING TO THE DEPENDENCE OF ANY KIND OF KNOWLEDGE.

PALAVRAS-CHAVE: POESIA - CABO VERDE - LEGITIMIDADE - EXTERIORIDADE KEYWORDS: POETRY - CABO VERDE - LEGITIMITY - EXTERIORITY 


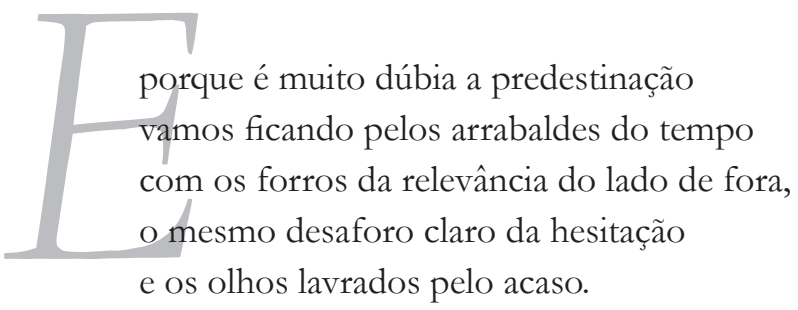

Os textos que verdadeiramente importam, aqueles com os quais se pode continuar a pensar, têm força suficiente para existir distantes dos consensos, das anamneses e dos anúncios proféticos. O seu tempo é outro. Pretendese aqui reflectir sobre essa força de ruptura que não precisa de nada que a acrescente ou intensifique, mas está ela mesma disponível para múltiplas exapropriações. Parte-se da leitura da poesia de João Vário (João Manuel Varela, 1937-2007), poeta caboverdeano.

Um dos principais problemas dos estudos de literatura é o da legibilidadeilegibilidade desta: é que se por um lado há um direito à literatura como direito à ilegibilidade - aceitação de operações incontroláveis da imaginação e de dicções perturbadoras da sintaxe -, por outro lado esse direito é confiscado por dispositivos cuja função é fundamentalmente sobrepor ao ilegível um conjunto de qualidades, e por conseguinte de finalidades. Conferindo relevância social ao literário, para em seguida o diluir numa escala de valores consensual, ou pretendendo salvaguardá-lo como uma relação especial com a verdade, esses dispositivos correspondem efectivamente a orientações do pensamento que não abdicam de fazer prevalecer um tipo de discurso ("científico", ou "filosófico"), que pretende deter a verdade de todas as manifestações discursivas. Tal prevalecer está em perfeita cumplicidade com os diversos modos de atribuir à literatura o lugar do sem-sentido que oculta uma verdade superior, final, de tipo histórico, oracular ou messiânico. Os enquadramentos históricos, o estabelecimento de linhagens e todos os expedientes que tomam os textos literários como antecipação de verdades ou lugar de produção de conhecimento (que pode ser apenas conhecimento de um uso mais perfeito da linguagem) são modos de usar esses textos para "descobrir" o que certas orientações da filosofia, da antropologia ou de outras ciências humanas autorizam a encontrar. Mesmo quando se considera um texto na perspectiva de uma interrogação da linguagem, o que se coloca com mais frequência é a pretensão (característica de certa orientação filosófica) de, por esse meio, compreender a essência dela. 
Se efetivamente se dá importância aos textos literários, eles não podem ser colocados na dependência de qualquer saber, o que significa que não confirmam nem antecipam - a sua repetição é criadora, como o é a da filosofia, trata-se de deslocação, desvio, metamorfose, devir.

Na citação de João Vário, colocada como epígrafe deste texto, há uma associação entre predestinação e relevância que não só indica uma ruptura com a doxa, mas afirma que a poesia se faz nos "arrabaldes do tempo" - fora da história como centro organizado/organizador, lugar de quem nela não tem lugar, voluntária ou involuntariamente. "Os arrabaldes do tempo" são a disponibilidade que precisa de infinitamente se construir, que precisa do desaforo da poesia - a recusa do medo, uma coragem que nada deve ao heroísmo convencional, e que é ela mesma recusa da dívida - "o mesmo desaforo claro da hesitação / e os olhos lavrados pelo acaso". Sair do paradigma da dívida, tal é a conjugação de "desaforo" e "hesitação", ligados da maneira mais improvável pelo adjetivo "claro", aquele que permite a passagem e ao mesmo tempo a obscurece. Em toda a poesia deste autor encontramos o mesmo imenso obstáculo à decifração - perseverança na opacidade, que se gera pela reflexão que hesita e pela atenção ao que vem, o nascer do mundo, na sua irreconhecível e demasiado próxima escrita. Estamos perante uma afirmação da poesia como enigma desencadeador de enigmas, isto é, como pensamento inspirador de pensamento.

Exemplo Geral, publicado em 1961, foi o primeiro de uma série de livros de João Vário cujos títulos têm em comum a palavra "exemplo" e que repetem uma estruturação onde consta uma ode inicial e uma divisão do poema em cantos. Desde logo aí a poesia é pensamento da mortalidade como o que permite o pensamento, que dela vem e por ela se dissemina sendo o que sustenta a rememoração enquanto relação com o que não se fixou e continua, vário, em diferendo com a "memória, memórias" oficiais. Com efeito, qualquer que seja a perspectiva, de decadência ou de progresso, na qual se constrói uma história como registo e acumulação de memórias, estas são declaradas "Como salário ou cântaros de sacrifício, /"Humanas razões de censura e audiência” (Vário: 1966, 14).

O "exemplo" do discurso poético nada tem de memorável. Pelo contrário, nele a memória do imemorial é fator de desvio ao contexto habitual, em que o homem (as suas ações, o seu caráter ou os seus sentimentos) é constituído como exemplo moral e pedagógico. Daí que os Exemplos estejam em ruptura com a exigência de verosimilhança e que o seu modo narrativo venha sobretu- 
do acentuar uma continuidade rítmica e fônica que suporta a singularidade do canto, o seu ser múltiplo e variante, nem verosímil nem inverosímil. Há nisso um desígnio de exatidão, prosseguido de livro para livro e indicado pelo adjetivo que se acrescenta à palavra "exemplo" para formar o título - geral, precário, próprio, relativo, maior, dúbio, coevo, irréversible, restreint - Neste aspecto, como noutros, as indicações de João Vário em notas que introduzem os livros, são importantes e fazem parte de um esforço de inteligibilidade, que persiste em aliança com o afastamento incessante dos padrões de comunicabilidade.

No prefácio a Exemplo Próprio, sublinha-se o propósito de "narrar o homem na sua singularidade", não pelo traçado de uma autobiografia, mas pela escrita de si na dispersão, pelo tornar-se vário: único e múltiplo, interminável, indeterminável. Aí se coloca o discurso poético como um contínuo desdobrar entre o fazer e a observação desse fazer enquanto multiplicação de linguagens que cria o próprio-múlptiplo:

[...] há um nível ou momento da transformação, diria melhor, da transmigração, em que o discurso poético, a arte de legar, instituir ou fazer o verbo, de transcrever a introspecção ou a percepção é hermética espectadora da sua própria faina, da sua disputa, da sua pessoa, da sua anónima multidão. Parece certo, de resto, que esta é uma das maiores e mais secretas ambições de toda a arte: transformação do singular na multidão, a colectivação, por assim dizer, do eu - Ó universo eu sou-te, diz Pessoa. Todos nós transportamos em nossa vida interior uma multidão privada, assegura-se; porém raros somos os que lhe damos a palavra ou a largamos à tona do mundo, para que o seja" (Vário, 2000: 126).

Dar a palavra ao múltiplo, é assim o próprio da poesia: criação de hermetismo, criação do mundo.

O múltiplo não se apresenta como tal, nem espontaneamente. Intuir e observar são operações de uma arte de escrever sem qualquer garantia, suportada pela expectativa que nada espera, mas que vem da linguagem, na qual a condenação à repetição é também ocasião do aleatório, possibilidade de romper com a História como sistema cronologicamente ordenado e orientado para uma realização final. Pelo pacto entre a linguagem e a natureza, o mundo é inesgotável - repetição como diferenciação sempre diferida. Quem escreve, escreve "pelos interstícios da vida, sobre os interstícios da vida" (Ibidem): nada se apresenta 
idêntico nesse gesto que contraria a entropia, e que é experienciado pelo sujeito enquanto consciência unificadora como uma operação amarga.

Trata-se da construção de um estilo que permita retirar-se da vinculação a finalidades e perseverar no devir de modo a que nenhuma voz se sobreponha em definitivo a outra: a linguagem da observação não diz a verdade do fazer hermético, mas acompanha-o no movimento do ampliar, do encontrar novas configurações, em diálogo, sem hierarquias.

Essa dualidade da composição poética, prosseguida por duas vias que se contaminam - por um lado narrativa e desencadear de imagens, por outro reflexão - é apresentada no prefácio anteriormente referido, colocando-se em absoluta continuidade a necessidade de conceptualização e a de afirmação da opacidade: "Se quisesse reunir o que venho escrevendo, poderia afirmar isto: onde se lê EXEMPLOS pode ler-se INVESTIGAÇÕES: investigações feitas com utensílios fornecidos pela memória: sobre a morte (Exemplo Geral), sobre as cidades, as mulheres, um certo Ocidente (Exemplo Relativo), sobre a predestinação (Exemplo Dúbio), sobre a cidadania (Exemplo Próprio), etc. O resultado é, evidentemente, como em muita investigação, um discurso (e/ou interpretação) e, nesse caso, de discurso metafísico se trata.

O homem é um ser duma considerável espessura, é óbvio. $\mathrm{Na}$ minha poesia, cuja preocupação maior é traduzir essa espessura, o próprio movimento e a estrutura do discurso poético devem sugerir tal opacidade ontológica, ao mesmo tempo que a veiculam, ou justamente porque a veiculam, ou a falam, a acompanham (no sentido musical da palavra). Daí o seu ar voluntariamente compacto, prolixo, barroco. De resto, rara é a poesia (ou arte) que, com tais propósitos, não seja, não se apresente mais ou menos 'barroca'. Será necessário mais uma vez, citar Whitman, Perse, um certo Eliot? Nada há de novo, pois, nesta atitude senão que (poderia acrescentar chocarreiramente) ela parte de mim, é minha, por minha vez (op. cit., 127).

Fazer de si um ponto de encontro das forças do universo: programa que em João Vário se coloca como oposição ao niilismo, sem que para isso se proponha uma nova escala de valores ou um qualquer ideal, mas em que se prossegue a construção de passagens e a variação que o tempo da repetição (o tempo "próprio") dá ao que se repete. Assim se esclarece obscurecendo e 
vice-versa, o que, nos termos de João Vário, parte de uma crença no humano, a de que este "guarda a cem chaves uma intensidade ofuscante, esgotante, a única que pode cegar a morte, cansar a facilidade e estender, entendendo, os pactos plurais."

No intervalo em que as identidades se perdem, e com elas a relevância (do conhecimento, social) - "Toda a terra é amarga, amalgama", é o primeiro verso de Exemplo Próprio - aí mesmo se abre a perplexidade: "Ah homem a que cultura pertences? / Que continente, que passado, que tradição/ te modelaram?" A resposta a essa pergunta não está na exclusão de memórias, mas na multiplicação-dispersão delas no encontro que o desejo e a contingência propiciam. Essa é uma afirmação de cosmopolitismo como miscigenação do imortal ("A imortalidade não cega: só cumpre a vida como vida"), como aquilo que subtrai a terra ao comércio das pertinências instituídas e das exclusões e negações de que são solidárias: a do acaso, a do tempo como abertura criadora.

Num texto publicado em 1961 na revista $\hat{E} x o d o n^{\circ}$ 1, Coimbra, João Vário, citando Eliot, defende a concepção de que o todo da literatura "tem uma existência simultânea e compõe uma ordem simultânea" e de que o sentido histórico que permite afirmar a simultaneidade é aquele que permite ao escritor ter consciência do seu tempo. Essa concepção em que o intemporal (o que se repete em qualquer tempo) e o temporal (histórico, contextual) se reúnem, está na base de uma idéia do herdar enquanto perseverar, investigar, deslocar, o que é acima de tudo um romper com o idêntico, retirar-se à personalidade (fosse ela a mais dilacerada) e à ordem temporal, sem que tal corresponda a qualquer programa de evasão. Pelo contrário, trata-se de abrir o presente-futuro, construindo-o como repetição que difere, que está fora de qualquer Lei, e constitui a decisão da poesia, a sua natureza ética que a subtrai ao conhecido, ao relevante enquanto esperável, verosímil, aceitável.

Nem legível, nem integrável sem resto num conjunto de operações intertextuais, embora estas sejam aí muito abundantes, a leitura da poesia de João Vário conduz-nos insistentemente à derrapagem do sentido aí mesmo onde ele se faz, onde o mundo é criado. Nela não há estabelecimento de endereços fixos, nem construção do comum, nem estabelecimento de simetrias: os ritmos e linguagens em divergência compõem poemas longos onde a grandeza da obstinação, dando-se como perdida a conta do destino, encontra o vigor (desejo que deseja) que a continuidade narrativa suporta e em si transporta. $\mathrm{O}$ 
fluxo da escrita é então um espaço de exaltação da vida, que se distancia das estratégias guerreiras e de conquista que fazem parte da memória do ocidente, dos seus livros canônicos:

Em verdade, em verdade, toda a vida

Vale o espaço do pão que não foi amedrontado

Tal o vigor é afinal uma porta aberta

Sobre o mel, a fidelidade (Vário, 1998: 39)

Através da narrativa todo o narrado existe dirigindo-se ao outro, sempre outro, e por isso nunca contemporâneo, embora sejam as mesmas muitas das datas referidas. É que da indagação de uma data faz parte o que foi depois e o que ela foi no que foi depois. Assim do ano 1937, ano do nascimento do poeta, não é a determinação da "quantia da sua contingência", que efectivamente importa, mas sim lançar os dados para o pensamento de tantos contrastes. Através da enumeração do terrível, do grandioso e do enigmático, o que fica é a pertença a diferentes tempos que não se pode deixar apaziguar: "aquele dentre nós que tiver o entendimento pronto,/ afastar-se-á, quando passarem espalhando o acordo e o nexo" (op.cit., 47)

Manter o diferendo, a irredutibilidade dos tempos que os homens têm em comum, será esse o desígnio da literatura que irrompe no tempo histórico, mas sem lugar nele, vindo, na fragilidade quotidiana, perturbar "os trabalhos e os dias", alterando-os no movimento que lhes propicia a comparência. As noções de contemporaneidade da literatura e de literatura contemporânea iludem esse diferendo ao pretenderem vincular a literatura a um tempo, uma época, um contexto, fazendo-a expressão desse tempo, o que é tomá-la como certa e legível. E quando uma poesia deixa de ser incerta, isto é, quando já foi classificada como património definitivo, havendo só que propor novas perspectivas de leitura ou interpretação, tal significa que já foi capturada para construtora de consensos ficando apenas sujeita a revisão em função destes.

$\mathrm{Na}$ verdade aquilo que torna impossível qualquer estabilização de um texto poético ou literário é aquilo que o faz nascer, a indissociabilidade do poético e do não-poético, evidenciada com Baudelaire, e sobre a qual Eliot escreveu: «Com ele [Baudelaire], como com Laforgue, aprendi que o gênero de materiais que tinha, o gênero de experiência que um adolescente tivera 
numa cidade industrial da América, podiam ser os materiais da poesia; e que a fonte da nova poesia talvez se descobrisse naquilo que fora considerado até agora como o impossível, o estéril, o não poético intratável. Que, de fato, a obrigação do poeta era criar poesia a partir dos recursos inexplorados do não poético; que o poeta, de fato, estava comprometido pela sua ocupação a transformar o não-poético em poesia" (Eliot, 1992: 162).

O problema está no fechamento que, no enunciado acima, a palavra "transforma" dá à relação entre poético e não-poético, assim libertando aquele deste: se a poesia é potencial de transformação que impede a simples herança e, pelo contrário, exige esforço, é porque nela há tensões irresolúveis, jogos de forças - a significância, que propicia o deslocamento, em suma, a abertura que a desvia, a impede de ser idêntica a si-mesma. Não se pode tratar de transformar uma coisa na outra, mas uma e outra, ou seja, pelo fazer, desencadear o poético - encontro da finitude e do infinito imanente à existência do homem. Na sua condição de intransmissível, a poesia tem já inscrito o nãopoético: opacidade da linguagem que não vem da própria linguagem, mas do que a perturba, do que impede o que através dela se faz automatismo.

O pensamento da literatura não a encerra em si, numa pretensa autonomia: não se limitando a ser indagação da linguagem pela linguagem, ele expõe a não-unidade desta (a ausência de uma metalinguagem), colocando como ponto de partida de todo o dizer a possibilidade de desdobramento infinito, sem centro, que faz com que referência e significação (ou sentido) sejam traços descontínuos da energia da escrita, da sua significância, relação na linguagem com o de-fora, o qual não sendo um exterior da linguagem que se dê enquanto tal, isto é, sem ela, nela se torna eminente em interrupções que se manifestam como gaguez, murmúrio, canto, introduzindo explosões, deslocamentos, voltas e reviravoltas imprevisíveis.

A evidência para o homem moderno de uma mortalidade sem heroísmo nem resgate tornou-se exigência de pensamento poético para o qual é decisivo o movimento de desvio do entusiasmo como dissolução mística e a perseverança e sobriedade que se obstinam na finitude e, conseqüentemente no histórico, no que, sendo contingente e efêmero, nada é sem a relação de infinito em que se tece e de que se tece a sua inesgotabilidade. A poesia exige então um fazer, o "cálculo do poeta", no dizer de Hölderlin, que é sem garantia, pois a finitude implica a permanente reapropriação como uma ex- 
apropriação, um sair do próprio. Pela organização e escolha vocabular, nomeadamente pelas repetições e pelo constante, mas quase imperceptível, desvio à organização lógica da frase, a poesia dos Exemplos afirma-se como testemunho impossível, testemunho do desconhecido, de que não há testemunho, em que o dizer se obstina na passagem que suspende o limite entre o poder e o não-poder da linguagem. "Testemunho", "mortalidade"e "perseverança ", são algumas das palavras que, a par da expressão "em verdade", retornam de livro para livro e se repetem em cada um, sinalizando um movimento em que a exactidão é uma questão de multiplicar caminhos exaurindo-os como meios para qualquer finalidade, deixando que de tudo fique o que não é dito - o passo que permite continuar: «E assim de nós o que nos abdicamos / absolve a ofegante identidade/ Que sofremos» (Vário, 1966: 27)

Multiplicando as referências poéticas e culturais, para as quais não se encontra uma medida comum, os Exemplos dão conta de um desejo de perseverar no estudo, de não iludir a importância das respostas, pelo contrário, de a expor, fazendo dessa exposição também a da sua insanável insuficiência. Esse estudo parte tanto de fait-divers como dos grandes fatos, ambos susceptíveis de assinalar o que numa época foi abertura ao devir em aliança com um desejo de justiça, ou o que foi desencadear da pulsão de morte, fosse ele minuciosamente construído ou espontâneo. Em Exemplo Coevo, o recurso à narração de grandes factos da história segue o desígnio de investigação do ano de 1937, ano do nascimento do autor, pormenor entre outros que igualmente apontam a humildade da investigação, o não poder ela ser feita do alto, do lugar da omnipotência, mas de se seguir da existência, e de serem as suas circunstâncias sempre mistura, onde o que mais decisivamente afeta não é necessariamente o mais próximo em termos cronológicos. A dimensão épica, narradora, da poesia, surge então como salvaguarda de qualquer tentação doutrinária ou totalizadora: as significações de que os fatos históricos estão, por definição, investidos, perdem a sua força constrangedora quando fazem parte de uma estruturação que não só não se vincula a uma hierarquia, mas interrompe a ordenação histórica, desde logo porque é no exemplo, no assim, aqui (espaço-tempo do poema), que os fatos são citados a comparecer e é, por conseguinte, o jogo único de afinidades, contrastes e ressonâncias que os integra como referências para o pensamento. 
como a deferência, a referência, a tarefa exemplar reflectem a ingenuidade e o esforço com que durante todo o nosso tempo de vida deixarmos atenuar junho, setembro, o ventre de tal gravidez, a ilha insossa e o pânico hoje rememorado como uma baía com muita brisa preliminar, tal há uma madeira, uma maneira, uma urgência para inscrever os nomes de todos os que nos precedem ou na morte nos seguem e nem deus o sabe porque é menos imortal que a esperança e só se diz do arrojo dessa peculiaridade o que escapa ao património comum do espanto e do milagre que cada elo urdem entre os humanos desígnios. Que é como quem diz: tudo o que assim acontece sucessivamente a terra fecha do lado da liberdade e premedita. (Vário, 1998: 66)

Não podendo ser entendida como adequação dos enunciados ao mundo (o que assentaria na ilusão de haver um mundo exterior aos enunciados que dele fazem parte e o colocam como tal), a referência também não pode ser entendida como componente de um modo de fazer mundos (ou um mundo de mundos), pelo que isso implica de redução a uma perspectiva instrumentalizadora e pragmática. Com mais exactidão se poderá dizer que a referência poética desfaz mundos, pois enquanto atenção à finitude ela é acima de tudo atenção às transformações no espaço-tempo, que se dá como implicação e promessa de implicação nele pela saída dele, como esperança que persiste através do canto e do pensamento, depois de tudo, depois de não haver qualquer razão para o canto e o pensamento. 
(..)

Mas hemos de acrescentar o hino ao hino,

o signo ao signo, a mó à mó

como o pão se gasta para atenuar

a vetustez do mundo. Ah dizemos bem.

não há expectativa que invente

a medida para esta bebida

entre foice e erva, entre a multidão e o desdém,

e, contudo, a vocação

bebe onde o mundo não quer

nem predissera, porque bebe deus

e parte de seu caos, essa parte

que escapa à causalidade e à profecia.

(...) (Vário, 2000: 106)

\section{Referências Bibliográficas}

ELIOT, T. S. Ensaios escolhidos. Trad. Maria Adelaide Ramos. Lisboa: Cotovia, 1992. VÁRIO, João. Exemplo geral. Coimbra: Textos Êxodo, 1966. . Exemplo coevo. Praia: Spleen, 1998.

. Exemplo próprio. Mindelo: Pequena Tiragem, 2000. 